\title{
Stakeholders' perception about aflatoxin contamination in groundnut (arachis hypogaea L.) along the value chain actors in eastern Ethiopia
}

\author{
Ephrem Guchi
}

\begin{abstract}
Background: Groundnut is an important cash crop for domestic markets as well as for foreign trade in several developing and developed countries. It is also one of the most valuable cash crops in eastern Ethiopia. However, its production is constrained by Aspergillus species, which cause quantitative losses and produce highly toxic and carcinogenic chemical substances known as aflatoxins. The research was conducted with the objective to determine the stakeholders' perceptions about groundnut qualities with respect to aflatoxin contamination and pre-and post-harvest practices affecting development of aflatoxigenic fungi and aflatoxin contamination. The study was conducted in groundnut growing areas in eastern Ethiopia. Primanry data were collected using a semi-structured self-administered questionnaire administered to 165 randomly selected stakeholders.
\end{abstract}

Results: We found that from 165 respondents, $98.7 \%$ farmers and $93.3 \%$ traders disagreed on the indices of groundnut quality assumed of promoting aflatoxin contamination.

Conclusions: It is necessary to make concerted campaigns to create and raise perception among farmers, traders and consumers about pre-and post-harvest practices affecting groundnut quality and aflatoxin contamination and high quality maintenance in the groundnut value chain.

Keywords: Aflatoxin; Ethiopia; Groundnut; Perception; Value chain actors

\section{Background}

Groundnut (Arachis hypogaea L.), which is also known as peanut, earthnut, monkeynut and goobers, is an annual leguminous oil crop. It is one of the world's most important oilseed crops (Upadhyaya et al., 2010), ranked as the 4th most important oilseed crop and the 13th most important food crop (Surendranatha et al., 2011). It is currently grown on 25.2 million hectares worldwide with a total production of 35.9 million metric tons, with developing countries in Asia (66 \%) and Africa (25\%) as the major producers. Groundnut kernel contains $40-50 \%$ fat, $20-50 \%$ protein and $10-20 \%$ carbohydrate and is rich in vitamins and minerals (USDA, 2010).

Groundnut is relatively new to Ethiopia. It was introduced in the early 1920s (Daniel 2009). Its production is expanding and has a huge potential as a cash and food crop to improve livelihoods of farmers and traders in Ethiopia.

Correspondence: ephremg21@gmail.com

Department of Applied Biology, Samara University, School of Natural and Computational Sciences, Samara, Ethiopia
However, its yield and quality is constrained by both abiotic and biotic factors. In addition to yield and quality loss due to fungal diseases, infection of groundnut seed by Aspergillus flavus Link ex Fries and Aspergillus parasiticus Speare result in contamination of the seed with aflatoxins (Afs), which are toxic fungal metabolites (mycotoxins). Aflatoxin contamination of agricultural crops, such as groundnut and cereals, causes annual losses of more than US\$750 million in Africa and more than US\$100 million per year in USA (Kamika and Takoy, 2011).

Developing countries account for approximately $95 \%$ of the world groundnut production, but are unable to sell large quantities of groundnut on the international market because of aflatoxin contamination (FAOSTAT 2010). In Ethiopia, Groundnut market is declining and export of the crop has come to a standstill to date. This is because of aflatoxin contamination of the crop and the difficulty of meeting tolerance limits demanded by importers and food processors, leading to rejection of the crop and reduction in the local and world markets. 
For instance, a food processing company in Ethiopia imported groundnuts from India, while groundnut producers in in Eastern Ethiopia could not find market to sell their crop (Amare Ayalew, personal communication).

Aflatoxins are widly known mycotoxin contaminants that are most commonly associated with groundnuts (Dohlman 2003). Aflatoxin contamination of agricultural commodities poses considerable risk to human and livestock health and has a significant economic implication for the agricultural industry worldwide Richard and Payne (2003). Aflatoxins are acutely toxic, immunosuppressive, mutagenic, teratogenic and carcinogenic compounds targeting mainly the liver for toxicity and carcinogenicity (Woloshuk et al. 2009).

The level of aflatoxin awareness in many developing countries is extremely low or non-existent altogether. Poor knowledge of the aflatoxin and its health risks causes consumers to be exposed to acute and chronic toxicity through consumption of poor quality or moulded groundnuts (James et al., 2010). Outbreaks of acute aflatoxicosis from contaminated groundnut in humans have been documented in Kenya, India, Malaysia and Thailand (CAST, 2003). One of the first major documented reports of aflatoxins in humans occurred in 150 villages of western India in 1974 where 397 persons were affected and 108 died (Krishnamachari et al., 1975).

Aflatoxin contamination of groundnut could occur before harvest while the crop is at maturing stage in the field, particularly favored by drought stress and high soil temperature, in storage and during marketing (CAST, 2003; Mutegi et al., 2009; Abdi and Alemayehu 2014). It can occur on pods and seeds in the soil near harvest, during harvest, and post-harvest in storage. It could occur during all stages along the groundnut value chain. Therefore, studies that address the entire groundnut value chain covering major nodes from production through storage to consumption (markets) are necessary, since they could support decision making targeting major points of aflatoxin contamination and averting its negative consequences.

Information on aflatoxin contamination of groundnut and the associated fungi and health risks in Ethiopia is scant, confined to limited market samples, and does not particularly address the situation at harvest. There is a need for identification of the gaps in producers'/traders' and consumers' perception about the aflatoxin generation and/or contamination problem and its causal/ contributing factors. The objective of the present study was to determine the stakeholders' perceptions about groundnut qualities with respect to aflatoxin contamination and pre-and post-harvest practices affecting development of aflatoxigenic fungi and aflatoxin contamination.

\section{Materials and Methods}

\section{Description of the study area}

The study was conducted in three major groundnut growing areas, namely Babile, Gursum and Fedis Districts of East Hararghe Zone, Oromia Regional State of Ethiopia in 2014 crop season. The areas were selected purposively as they represented the bulk of groundnut production in Ethiopia. These areas have high potentials for rain fed groundnut production nationally. Descriptions of the study area are described in Ephrem et al. (2014).

\section{Study methodology}

The groundnut value chain in eastern Ethiopia comprises farmers, traders (wholesalers and retailers); rural, urban and semi-urban markets, and consumers. Descriptions of the groundnut value chain are described in Ephrem et al. (2014).

A key informant interview was used to gather primary data on stakeholders' perceptions using questionnaires. Apt questionnaires for different stakeholders were developed, pre-tested and used in the data collection. Where applicable, the questionnaire survey was conducted at the time of the postharvest groundnut sample collection and stakeholders who provided groundnut samples served as key informants in the interview. The questionnaire was developed after pre-tested through conducting a focused group discussion and interview involving farmers, traders, supporters, village elders, some community leaders and provincial administration staff. The results of the discussion were used to formulate the survey questions and respondants who percived the situations were selected purposively. These were the criteria that I was used in inclusion and exclusion of respondants. Items defining perceptions of Aflatoxin in groundnuts were measured on a 5-point Likert scale. The questions were designed in a way that each element of the question represented a statement the respondents would have made if asked a question. This was done to minimize respondent bias (Ajzen 1991).

\section{Data collection procedure}

Four field assistants were selected by the researcher to aid in data collection. They were trained by the researcher to understand the objectives of the study and the purpose and procedure of the interview process; to have a common understanding of the questions in the interview schedule; and to ask the questions to the understanding of the respondents. The field assistants were selected based on their knowledge of the local language, previous research experience and ability to understand and write in the local dialect and English. The instruments were explained to the respondents in their local dialects which include Amharic and Oromifa. Responses 
were then recorded in English by the field assistants for easy use by the researcher.

\section{Data analysis}

Data collected from the questionnaires including sociodemographic characterstics of respondents, perceptions on indices of groundnut quality, pre- and post-harvest practices of groundnut and associated factors were summarized and analyzed using Statistical Package for Social Sciences (SPSS). Descriptive statistics in the form of frequencies and means were used to analyze the data obtained.

\section{Results}

The socio-demographic characteristics of the groundnut value chain actors in the study areas have been depicted in Table 1. It was observed that farmers in the study areas had the highest number $(53,70.7 \%$ ) of male headed households, while the traders had the lowest number $(7,23.3 \%)$. Also, the majority of the value chain actors were between the ages of 35 and 50 years old, particularly farmers (61.3\%) and traders (53.3 \%). A significant number of farmers (30.7 \%) tended to be somewhat younger with nearly below 35 years of age. Most of the value chain actors were married, particularly farmers (54.7\%). However, almost a third of farmers (37.3 \%) were single or unmarried and 15 (50.0\%) supporters and consumers were single and unmarried.

A large number of respondents along the value chain had no formal education (i.e. they were illiterate), especially $68.0 \%$ of the farmers with variable household incomes. In contrast, $32.0 \%$ of farmers, $56.7 \%$ of traders and more than $33.3 \%$ of consumers had at least attended primary education. However, all 30 (100\%) of supporters had teritiary education. With regard to household incomes, 46 (61.3\%) farmers earned between ETB 3000 to 10,000 per month. Traders and consumers had the lowest income with $4(13.3 \%)$ and 5 (16.7 \%) earning less than ETB 3000 per month, respectively. With regard to years of experiences, 64 (85.3\%) of farmers had farming for more than 10 years, whereas most supporters $(16,53.3 \%$ ) had between 5 to 10 years of farm experience.

Perception of groundnut quality among actors of the groundnut value chain has been summarized and tabulated (Table 2). The tabulated indices are conditions necessary for aflatoxin contamination in groundnut and reduction in the quality of groundnut due to contamination by aflatoxin, making them unattractive to buyers and unhealthy for human consumption. The absence of these variables in groundnuts obviously reduces aflatoxin contamination.

Table 1 Socio-demographic characterstics of interviewed respondents $(n=165, \%)$ in eastern Ethiopia in 2014

\begin{tabular}{|c|c|c|c|c|c|c|c|c|c|}
\hline \multirow[t]{2}{*}{ Variables } & & \multicolumn{2}{|c|}{ Farmers } & \multicolumn{2}{|c|}{ Traders } & \multicolumn{2}{|c|}{ Supporters $^{a}$} & \multicolumn{2}{|c|}{ Consumers } \\
\hline & & $\mathrm{N}$ & $\%$ & $\mathrm{~N}$ & $\%$ & $\mathrm{~N}$ & $\%$ & $\mathrm{~N}$ & $\%$ \\
\hline \multirow[t]{2}{*}{ Sex group } & Male & 53 & 70.7 & 7 & 23.3 & 18 & 60.0 & 13 & 43.3 \\
\hline & Female & 22 & 29.3 & 23 & 76.7 & 12 & 40.0 & 17 & 56.7 \\
\hline \multirow[t]{3}{*}{ Age group } & $<35$ years old & 23 & 30.7 & 11 & 36.7 & 9 & 30.0 & 11 & 36.7 \\
\hline & $35-50$ years old & 46 & 61.3 & 11 & 36.7 & 16 & 53.3 & 11 & 36.7 \\
\hline & $>50$ years old & 6 & 8.0 & 8 & 26.7 & 5 & 16.7 & 8 & 26.7 \\
\hline \multirow[t]{4}{*}{ Marital status } & Single & 28 & 37.3 & 11 & 36.7 & 15 & 50.0 & 15 & 50.0 \\
\hline & Married & 41 & 54.7 & 12 & 40.0 & 15 & 50.0 & 15 & 50.0 \\
\hline & Divorced & 6 & 8.0 & 6 & 20.0 & 0 & 0.0 & 0 & 0.0 \\
\hline & Widowed & 0 & 0.0 & 1 & 3.3 & 0 & 0.0 & 0 & 0.0 \\
\hline \multirow[t]{4}{*}{ Educational level } & No formal education & 51 & 68.0 & 9 & 30.0 & 0 & 0.0 & 6 & 20.0 \\
\hline & Primary education & 24 & 32.0 & 17 & 56.7 & 0 & 0.0 & 10 & 33.3 \\
\hline & Secondary education & 0 & 0.0 & 4 & 13.3 & 0 & 0.0 & 8 & 26.7 \\
\hline & Teritery education & 0 & 0.0 & 0 & 0.0 & 30 & 100.0 & 6 & 20.0 \\
\hline \multirow[t]{3}{*}{ Household income per month (ETB) } & $<3000$ & 22 & 29.3 & 4 & 13.3 & 11 & 36.7 & 5 & 16.7 \\
\hline & $3000-10,000$ & 46 & 61.3 & 11 & 36.7 & 10 & 33.3 & 15 & 50.0 \\
\hline & $>10,000$ & 7 & 9.3 & 15 & 50.0 & 9 & 30.0 & 10 & 33.3 \\
\hline \multirow[t]{3}{*}{ Years of experience } & $<5$ years & 1 & 1.3 & 8 & 26.7 & 10 & 33.3 & 11 & 36.7 \\
\hline & $5-10$ years & 10 & 13.3 & 11 & 36.7 & 16 & 53.3 & 11 & 36.7 \\
\hline & $>10$ years & 64 & 85.3 & 11 & 36.7 & 4 & 13.3 & 8 & 26.7 \\
\hline
\end{tabular}


Table 2 Perception of value chain actors $(n=165, \%)$ on the quality of groundnut in eastern Ethiopia in 2014

\begin{tabular}{|c|c|c|c|c|c|c|c|c|}
\hline \multirow[t]{2}{*}{ Indices of groundnut quality } & \multicolumn{2}{|l|}{ Farmers } & \multicolumn{2}{|l|}{ Traders } & \multicolumn{2}{|c|}{ Supporters } & \multicolumn{2}{|c|}{ Consumers } \\
\hline & Disagree & Agree & Disagree & Agree & Disagree & Agree & Disagree & Agree \\
\hline 1. Groundnuts which have a change in taste promote AF & 74(98.7) & $1(1.3)$ & 29(96.7) & $1(3.3)$ & $5(16.7)$ & 25(83.3) & 15(50.0) & $15(50.0)$ \\
\hline 2. Groundnuts which have a change in colour promote AF & 74(98.7) & $1(1.3)$ & 28(93.3) & $2(6.7)$ & $5(16.7)$ & 25(83.3) & $21(70.0)$ & $9(30.0)$ \\
\hline 3. Mouldy groundnuts promote AF & $75(100)$ & $0(0.0)$ & 29(96.7) & $1(3.3)$ & $5(16.7)$ & 25(83.3) & 14(46.7) & $16(53.3)$ \\
\hline 4. Broken and bruised groundnuts promote AF & 73(97.3) & $2(2.7)$ & $27(90.0)$ & $3(10.0)$ & $5(16.7)$ & 25(83.3) & 13(43.3) & $17(56.7)$ \\
\hline 5. Insect-attacked groundnuts promote AF & 74(98.7) & $1(1.3)$ & 28(93.3) & $2(6.7)$ & $5(16.7)$ & 25(83.3) & 10(33.3) & $20(66.7)$ \\
\hline 6. Shriveled groundnuts promote AF & 73(97.3) & $2(2.7)$ & $27(90.0)$ & $3(10.0)$ & $5(16.7)$ & 25(83.3) & $12(40.0)$ & $18(60.0)$ \\
\hline 7. Groundnuts stored damp promote AF & 74(98.7) & $1(1.3)$ & 29(96.7) & $1(3.3)$ & $5(16.7)$ & 25(83.3) & 15(50.0) & $15(50.0)$ \\
\hline 8. Groundnuts which contain foreign materials promote AF & 74(98.7) & $1(1.3)$ & 27(90.0) & $3(10.0)$ & $5(16.7)$ & 25(83.3) & 13(43.3) & $17(56.7)$ \\
\hline
\end{tabular}

From 165 respondents, almost all farmers (98.7\%) and majority of traders (93.3\%) disagreed on consequences of the eight indices of the groundnut quality, including groundnut with a change in taste (organoleptic), a change in colour, mouldy growth, broken and bruised nuts, insect-attacked beans, shriveled kernels, stored damp and contained foreign materials (twigs, leaves, dead insects, sand, etc.) as they do promote aflatoxin contamination. It may be concluded that the majority of farmers and traders are at a great risk of aflatoxin contamination, whereas $83.3 \%$ of supporters agreed that all of the eight indices of the groundnut quality, such as groundnuts with a change in taste, a change in colour, mouldy growth, broken and bruised nuts, insectattacked beans, shriveled kernels, stored damp and contained foreign materials as they do promote aflatoxin contamination. This group would obviously reject groundnuts which contain one or two of the variables which project the possible presence of aflatoxin in groundnuts. Their perception of groundnut quality would influence their consumption habits and hence would reduce the risk of aflatoxicosis. This group, however, consists of only $83.3 \%$ and this shows that the habits of groundnut consumers in the region would largely expose the majority of the respondents to aflatoxin contamination.

The perception of farmers and traders on pre-and post-harvest practices that affect aflatoxin contamination has been tabulated (Table 3). About $92 \%$ of the respondent farmers and $83.3 \%$ of the interviewed traders dried their groundnut seeds in the open sun. About $86.7 \%$ of the farmers and $76.7 \%$ of the traders spread the groudnut seeds on the bare ground during drying. As many as $13.3 \%$ of farmers spread groundnuts on a raised platform above the ground. All the farmers and traders were involved in the storage of groundnuts. About $93.3 \%$ of the farmers and $66.7 \%$ of the traders stored groundnut in mixture with other $\operatorname{crop}(\mathrm{s})$ in previously used structures. According to the respondents, maize was reported to be the number one crop stored with groundnut. All the respondents stored groundnut in rooms dedicated to crop storage. The most commonly used storage material was the polythene sack, which was used by as many as $96.0 \%$ of the farmers and $70.0 \%$ of the traders. About $73.3 \%$ of farmers and $90.0 \%$ of traders told that they sorted their groundnut to attract customers or the market. Both farmers and traders mentioned that sorting fetches higher profit and averts health risks. However, the remaining farmers and traders explained that sorting groundnut is not only time consuming but also reduces groundnut quantity by at least $5 \%$ on average.

When supply chain actors were asked about the criteria used to identify spoiled groundnut, approximately $94.6 \%$ of the farmers and $80.0 \%$ of the traders reported a change in groundnut color as the obvious criteria used. The most common color changes indicated were brown, black and greenish. When supply chain actors were asked about what they usually do to spoiled groundnut, about $93.3 \%$ of farmers and $86.7 \%$ of the traders indicated that they would throw away or dump to garbage. However, $6.5 \%$ of farmers and $13.3 \%$ of traders told that they process spoiled or moulded groundnut into dawadawa (a spice used for stews, sauces and soups). Generally, the farmers were unaware of the important ways and means of management of pre-harvest and post-harvest aflatoxin contamination of groundnut.

When asked about the mechanical injury onto pods that leads to aflatoxin contamination, about $53.3 \%$ of the farmers and $66.7 \%$ of the traders had no appropriate replies to the question. Approximately, $66.7 \%$ of farmers and $83.3 \%$ of traders disagreed on the point that the end-of-season-drought for more than 20 days leads to aflatoxin contamination. However, this is an important reason for aflatoxin contamination in practice.

\section{Discussion}

Aflatoxins are the secondary metabolites of the fungi namely Aspergillus flavus and A. parasiticus. Aflatoxins 
Table 3 Farmers' and traders' perception on pre-and post-harvest practices that lead to aflatoxin contamination $(n=105, \%)$ in eastern Ethiopia in 2014

\begin{tabular}{|c|c|c|c|}
\hline \multirow[t]{2}{*}{ Questions } & \multirow[t]{2}{*}{ Responses } & \multicolumn{2}{|l|}{ Proportions } \\
\hline & & Farmers & Traders \\
\hline \multirow[t]{2}{*}{ 1. Do you dry nuts? } & Yes & $69(92 \%)$ & $25(83.3 \%)$ \\
\hline & No & $6(8 \%)^{*}$ & $5(16.7 \%)$ \\
\hline \multirow[t]{2}{*}{ 2. What drying method(s) do you use? Or are you aware of drying method(s)? } & Spreading on the ground & $65(86.7 \%)$ & $23(76.7 \%)$ \\
\hline & On raised platform & $10(13.3 \%)$ & $7(23.3 \%)$ \\
\hline \multirow[t]{2}{*}{ 3.Do you store in mixed used structures? } & Yes & $70(93.3 \%)$ & $20(66.7 \%)$ \\
\hline & No & $5(6.7 \%)$ & $10(33.3 \%)$ \\
\hline \multirow[t]{2}{*}{ 4. What storage method do you use? } & Polythene sacks & $72(96 \%)$ & $21(70 \%)$ \\
\hline & Jute sacks & $3(4 \%)$ & $9(30 \%)$ \\
\hline \multirow[t]{2}{*}{ 5. Do you sort nuts? } & Yes & $55(73.3 \%)$ & $27(90 \%)$ \\
\hline & No & $20(26.7 \%)$ & $3(10 \%)$ \\
\hline \multirow[t]{2}{*}{ 6. How do you identify spoiled nuts? } & Change in Color & $71(94.6 \%)$ & $24(80 \%)$ \\
\hline & Insect Infestation & $4(5.4 \%)$ & $6(20 \%)$ \\
\hline \multirow[t]{2}{*}{ 7. What do you do to spoiled nuts? } & Throw away & $70(93.3 \%)$ & $26(86.7 \%)$ \\
\hline & Processed to soup & $5(6.7 \%)$ & $4(13.3 \%)$ \\
\hline \multirow[t]{2}{*}{8 Does mechanical injury to pods lead to AF contamination? } & Yes & $35(46.7 \%)$ & $10(33.3 \%)$ \\
\hline & No & $40(53.3 \%)$ & $20(66.7 \%)$ \\
\hline \multirow[t]{2}{*}{ 9. Does end of season drought for 20 days lead to AF contamination? } & Yes & $25(33.3 \%)$ & $5(16.7 \%)$ \\
\hline & No & $50(66.7 \%)$ & $25(83.3 \%)$ \\
\hline \multirow[t]{2}{*}{ 10. Does aflatoxin contamination occur at any time during pre-harvest? } & Yes & $20(26.7 \%)$ & $3(10 \%)$ \\
\hline & No & $55(73.3 \%)$ & $90 \%)$ \\
\hline
\end{tabular}

*Respondants that uses nuts in boiled form but they knows methods of nut drying

are potent carcinogenic substances and have also been implicated in human diseases, like hepatitis B, and tuberculosis, by suppressing immune system. Perception of groundnut quality among actors of the groundnut value chain has been summarized and tabulated (Table 2). The tabulated indices are conditions necessary for aflatoxin contamination in groundnut and reduction in the quality of groundnut due to contamination by aflatoxin, making them unattractive to buyers and unhealthy for human consumption. The absence of these variables in groundnuts obviously reduces aflatoxin contamination.

From 165 respondents, almost all farmers $(98.7 \%)$ and majority of traders $(93.3 \%)$ disagreed on consequences of the eight indices of the groundnut quality, including groundnut with a change in taste (organoleptic), a change in colour, mouldy growth, broken and bruised nuts, insect-attacked beans, shriveled kernels, stored damp and contained foreign materials (twigs, leaves, dead insects, sand, etc.) as they do promote aflatoxin contamination. This observation is different from the report of Bonner and Nelson (1985) who asserted that high quality of food is most often associated with attributes such as rich/full flavor, taste, freshness, pleasant aroma and looks appetizing. This is because, in this case, the majority of the respondents did not measure the quality of the groundnuts on similar parameters. However, according to Holm and Kildevang (1996), individual assessments of quality are personal and situational, and that they are often based on incomplete information about the products they purchase. This may be the reason for this choice by the majority of respondents. Hence, these groups of consumers are, therefore, not likely to be protected from the negative aflatoxin effects through their groundnut consumption habits.

It may be concluded that the majority of farmers and traders are at a great risk of aflatoxin contamination, whereas $83.3 \%$ of supporters agreed that all of the eight indices of the groundnut quality, such as groundnuts with a change in taste, a change in colour, mouldy growth, broken and bruised nuts, insect-attacked beans, shriveled kernels, stored damp and contained foreign materials as they do promote aflatoxin contamination. This group would obviously reject groundnuts which contain one or two of the variables which project the possible presence of aflatoxin in groundnuts. Their perception of groundnut quality would influence their consumption habits and hence would reduce the risk of aflatoxicosis. This group, however, consists of only 
$83.3 \%$ and this shows that the habits of groundnut consumers in the region would largely expose the majority of the respondents to aflatoxin contamination.

The present study is similar with the findings of Harder (2005) who reported the factors used to measure the perception of groundnut quality include an increase in the level of aflatoxin contamination and fungal proliferation to a large extent when present in groundnuts. The perception of groundnut quality that the consumers generally hold, therefore, plays an important role in their groundnut consumption decisions, which could result in negative health implications some of which include liver cancer, stunted growth, increased prevalence of hepatitis, and low immune strength against HIV infection, among others.

The perception of farmers and traders on pre-and post-harvest practices that affect aflatoxin contamination has been tabulated (Table 3). About $92 \%$ of the respondent farmers and $83.3 \%$ of the interviewed traders dried their groundnut seeds in the open sun. About $86.7 \%$ of the farmers and $76.7 \%$ of the traders spread the groudnut seeds on the bare ground during drying. As many as $13.3 \%$ of farmers spread groundnuts on a raised platform above the ground. All the farmers and traders were involved in the storage of groundnuts. About $93.3 \%$ of the farmers and $66.7 \%$ of the traders stored groundnut in mixture with other crop(s) in previously used structures. According to the respondents, maize was reported to be the number one crop stored with groundnut. All the respondents stored groundnut in rooms dedicated to crop storage. The most commonly used storage material was the polythene sack, which was used by as many as $96.0 \%$ of the farmers and $70.0 \%$ of the traders. About $73.3 \%$ of farmers and $90.0 \%$ of traders told that they sorted their groundnut to attract customers or the market. Both farmers and traders mentioned that sorting fetches higher profit and averts health risks. However, the remaining farmers and traders explained that sorting groundnut is not only time consuming but also reduces groundnut quantity by at least $5 \%$ on average.

When supply chain actors were asked about the criteria used to identify spoiled groundnut, approximately $94.6 \%$ of the farmers and $80.0 \%$ of the traders reported a change in groundnut color as the obvious criteria used. The most common color changes indicated were brown, black and greenish. When supply chain actors were asked about what they usually do to spoiled groundnut, about $93.3 \%$ of farmers and $86.7 \%$ of the traders indicated that they would throw away or dump to garbage. However, $6.5 \%$ of farmers and $13.3 \%$ of traders told that they process spoiled or moulded groundnut into dawadawa (a spice used for stews, sauces and soups). Generally, the farmers were unaware of the important ways and means of management of pre-harvest and post-harvest aflatoxin contamination of groundnut.

When asked about the mechanical injury onto pods that leads to aflatoxin contamination, about $53.3 \%$ of the farmers and $66.7 \%$ of the traders had no appropriate replies to the question. Approximately, $66.7 \%$ of farmers and $83.3 \%$ of traders disagreed on the point that the end-of-season-drought for more than 20 days leads to aflatoxin contamination. However, this is an important reason for aflatoxin contamination in practice. The farmers' problem of awareness of this fact was due mainly to the lack of visual symptoms of aflatoxin contamination. A similar finding was reported by Kumar et al. (2001) who claimed that delayed harvesting was one of the major reasons for post-harvest aflatoxin contamination in groundnut. But, farmers disagreed with this aspect because delayed harvesting was a routine practice for them due to shortage of labour during peak harvest season. Also, $73.3 \%$ of farmers and $80.0 \%$ of traders replied that aflatoxin contamination does not occur at any time during pre-harvest operation in the field or growth period.

\section{Conclusion}

The occurrence of aflatoxins in agricultural commodities is a major health concern for livestock and humans. Aflatoxins are potent carcinogenic substance and have also been implicated in human diseases like hepatitis B and tuberculosis and can suppress immune system. Aflatoxins are secondary metabolites of the mycotoxigenic fungi, namely Aspergillus flavus and A. parasiticus. From 165 respondents, almost all (98.7 \%) farmers and $93.3 \%$ of the traders disagreed that the eight groundnut quality indices, including change in taste, change in colour, groundnut mouldiness, broken and bruised beans, insect-attacked kernels, shriveled kernels, damp stored grains and groundnuts containing foreign materials (twigs, leaves, dead insects, soil, and sand), etc. do not promote aflatoxin contamination.

Farmers and traders were ignorant of the important ways and means of pre- and post-harvest aflatoxin contamination of groundnut. When asked about whether or not mechanical injury to pods leads to aflatoxin contamination, about $53.3 \%$ of the farmers and $66.7 \%$ of the traders replied that no such effect occurs. Lack of awareness of farmers' was due mainly to lack of visual symptoms of aflatoxin contamination on the groundnut. The findings of the present study imply the need for launching a concerted campaign to augument awareness among the farming community, traders, consumers and similar end-users about aflatoxigenic fungi development, aflatoxin generation, contamination and management and quality maintenance in value chain of groundnut production and marketing. There is a need to explore 
the possibility of incorporating aflatoxin awareness into routine talk to increase the level of awareness of the stakeolders. It is recommended to discard groundnuts with a change in taste, a change in colour, mouldy growth, broken and bruised nuts, insect-attacked beans, shriveled kernels, stored damp and contained foreign materials as they do promote aflatoxin contamination and are highly risky to the health. It is also of paramount importance to create collaboration between agricultural and public health communities as well as among local, regional, national, international governing bodies and policy-makers for raising awareness of the different actors of the groundnut value chain. Further researches are also appealing and necessary for analyzing factors influencing individuals'beliefs and knowledge about the aflatoxin problem in Ethiopia; health risks, aflatoxigenic fungal development, generation, contamination and aflatoxin management in groundnut production and marketing business.

\section{Competing interests}

The author declares that he has no competing interests.

\section{Acknowledgments}

I extend my gratitude to Ministry of Education, Ethiopia for the financial support that provided.

Received: 12 February 2015 Accepted: 30 April 2015

Published online: 25 June 2015

\section{References}

Abdi M, Alemayehu C (2014) Incidence of Aspergillus contamination of groundnut (Arachis hypogaea L.) in Eastern Ethiopia. Afr J Microbiol Res 8(8):759-765

Ajzen I (1991) The theory of planned behavior. Org Beh Human Dec Pro 50:179-211

Bonner PG, Nelson R (1985) Product Attributes and Perceived Quality. In: Jacoby J, Olson J (eds) Foods in, Mass. Perceived Quality, Lexington Books, Lexington

CAST (Council for Agricultural Science and Technology) (2003) Mycotoxins: Risk in plant, animal, and human systems. Task Force Report No. 139, Arnes., p L4

Daniel E (2009) Groundnut research. In: Presentation for Workshop. Werer Agricultural Research Center, Ethiopia, pp 1-3

Dohlman E (2003) Mycotoxin hazards and regulations: Impacts on food and animal feed crop trade, International trade and food safety: Economic theory and case studies. In: Jean B (ed) Agricultural Economic Report 828. USDA, ERS

Ephrem G, Amare A, Mashilla D, Mengistu K, Belachew A, Chemeda F (2014) Stakeholders' awareness and knowledge about aflatoxin contamination of groundnut (arachis hypogaea L.) and associated factors in eastern ethiopia. Asian Pac J Trop Biomed 4(1):930-937

FAOSTAT (2010) Groundnut world production., http://www.faostat.fao.org) (Accessed on August 9, 2011

Harder B (2005) Farmers without fungus. Sci News 167(24):374, http://www.the freelibrary.com/Farmers+without+fungus:+how+to+store+peanuts+to+reduc+ toxinsa0133683421) (Accessed on February 14, 2008

Holm L, Kildevang H (1996) Consumers' views on food quality. A qualitative interview study. Appetite J 27:1-14, http://www.sciencedirect.com/ science?_ob=ArticleURL\&_udi) (Accessed on December 8, 2007

James B, Adda C, Cardwell K, Annang DM, Hell K, Korie S, Edorh M, Gbeassor F, Nagatey K, Houenou G (2010) Public information campaign on aflatoxin contamination of maize grains in market stores in Benin. Ghana and Togo Food Addit Contam 24(11):1283-1291

Kamika I, Takoy LL (2011) Natural occurrence of aflatoxin B1 in peanut collected from kinshasa, democratic republic of Congo. Food Contam 22:1760-1764

Krishnamachari KA, Nagaarajan V, Bhat RV, Tilak TB (1975) Hepatitis due to aflatoxicosis-an outbreak inWestern India. Lancet 305:1061-1063
Kumar VKK, Thakur RP, Desai S (2001) Prevalance of aflatoxin contamination in groundnut in Tumkur district of Karnataka, India. Int Arachis Newsletter 21:37-39

Mutegi CK, Ngugi HK, Hendriks SL, Jones RB (2009) Prevalence and factors associated with aflatoxin contamination of peanuts from Western Kenya. Int J Food Microbiol 130(1):27-34

Richard JL, Payne GA (2003) Mycotoxins in plant, animal, and human systems. Task Force Report No. 139. Council for Agricultural Science and Technology (CAST)

Surendranatha EC, Sudhakar C, Eswara NP (2011) Aflatoxin contamination in groundnut induced by Aspergillus flavus type fungi: a critical review. Int J of App Biol Pharm Tech 2:2

Upadhyaya HD, Reddy LJ, Gowda CL, Singh S (2010) Identification of diverse groundnut germplasm: sources of early maturity in a core collection. Field Crops Res 97:261-271

USDA (United States Department of Agriculture) (2010) National agricultural library nutrient database., http://www.nal.usda.gov/fnic/foodcomp/cgi-bin/ list_nut_edit.pl) (Accessed on July 5, 2011

Woloshuk B, Charles D, Kiersten W (2009) Diseases of mold: Purdue Extension publication BP-77 W., http://www.extension.purdue.edu/ extmedia/BP/BP-75-W.pdf. (Accessed Feb 2010)

\section{Submit your manuscript to a SpringerOpen ${ }^{\odot}$ journal and benefit from:}

- Convenient online submission

Rigorous peer review

- Immediate publication on acceptance

- Open access: articles freely available online

- High visibility within the field

- Retaining the copyright to your article

Submit your next manuscript at $>$ springeropen.com 